\title{
FEIRA DE CIÊNCIAS: UMA PROPOSIÇÃO METODOLÓGICA PARA ARTICULAR TEORIA-PRÁTICA UTILIZANDO O DIAGRAMA V
}

\section{LUCAS ANTONIO XAVIER}

Universidade Federal do Espírito Santo - Ufes

E-mail: lucas.perobas@gmail.com

\section{BRENO RODRIGUES SEgATTO}

Universidade Federal do Espírito Santo - Ufes

E-mail: breno.segatto@gmail.com

\section{LAÉRCIO FERRACIOLI}

Universidade Federal do Espírito Santo - Ufes

E-mail: laercio.ufes@gmail.com

\begin{abstract}
RESUMO
Este trabalho apresenta um estudo quali-quantitativo de atividades experimentais de fluidos e eletrodinâmica para a Feira de Ciências da Escola Estadual do Ensino Fundamental e Médio Professora Filomena Quitiba, situada no município de Piúma-ES, Brasil. As atividades desenvolvidas foram baseadas no Diagrama V, proposto por David Bob Gowin em 1977. Para infundir as ideias dessa heurística na Feira de Ciências foram ofertadas duas Oficinas Pedagógicas para os alunos do Ensino Médio que desenvolveram dez atividades tendo o Diagrama $V$ como procedimento norteador. Os dados foram coletados e avaliados durante todo o processo que, ao final, evidenciou o êxito na infusão da heurística de Gowin, uma vez que propiciou a práxis na construção do conhecimento. Portanto, os resultados revelam que os estudantes compreenderam a importância da dinâmica do Diagrama $V$ como instrumento referencial para os experimentos desenvolvidos para a Feira de Ciências.
\end{abstract}

PALAVRAS-CHAVE:

Feiras de Ciências; Diagrama V; Método Científico; Física.

SCIENCE FAIR: A METHODOLOGICAL PROPOSITION TO ARTICULATE THEORY-PRACTICE USING VDIAGRAM

\section{ABSTRACT}

This paper presents a qualitative and quantitative study with experimental fluid and electrodynamics activities in a Science Fair held in the State School of Elementary and High School Teacher Filomena Quitiba, located in the city of Piúma-ES, Brazil. The activities were developed based on the Diagram $V$, proposed by David Bob Gowin in 1977. To infuse the ideas of this heuristic at the science fair, two Pedagogical Workshops were offered to high school students who developed ten activities with Diagram $\vee$ as the guiding procedure. Data were collected and evaluated throughout the process, 
which, in the end, evidenced the successful infusion of Gowin's heuristic, as it provided praxis in the construction of knowledge. Therefore, the results reveal that the students understood the importance of the dynamics of Diagram $V$ as a reference instrument for the experiments developed for the Science Fair.

\section{KEYWORDS:}

Science Fair; V Diagram; Scientific Method; Physics.

\section{INTRODUÇÃO}

O ensino de ciências no Brasil vem, ao longo dos anos, passando por forte mudança em vista das novas práticas adotadas pelos educadores da área. Na busca por uma educação de qualidade, educadores e pesquisadores propõem novas metodologias com o objetivo de formar cidadãos com capacidade de atender às demandas da sociedade do século XXI. Nesse contexto as Feiras de Ciências apresentam-se como uma rota complementar para que os alunos observem o mundo por meio de uma ótica científica. Professores engajados nessa missão desempenham um papel relevante ao propor aos alunos projetos experimentais de Física para esses eventos.

Preocupado com o ensino de Física no Estado do Espírito Santo, Ferracioli (2012, pp. 36-40) faz a seguinte indagação: "Como preparar nossos cidadãos para uma sociedade cada vez mais complexa, onde o processamento da informação, geração de conhecimento e inovação são os principais critérios de valorização da mão-de-obra?"

O conhecimento técnico não é mais suficiente. É necessário ter uma visão analítica diante de dados e tomar decisões de maneira rápida, além de dominar a computação em nuvem, necessária na atualidade para o gerenciamento, segurança e mobilidade dos dados. Nessa perspectiva, a indústria 4.0, por exemplo, requer um profissional completo e que seja capaz de atender às novas demandas de uma sociedade em transformação.

Entretanto, como afirma Perez (2015), em pesquisa sobre o Indicador de Letramento Científico (ILC) da população brasileira, as "tarefas cotidianas, que 
envolvem a capacidade de usar conceitos e procedimentos científicos básicos, são de difícil realização para mais da metade (55\%) dos entrevistados". Esse dado aponta para a necessidade de desenvolvimento de novas metodologias que possibilitem melhores resultados.

Melhorar a qualidade da educação era uma das metas a serem cumpridas até 2015, almejados pelo documento "Educação para Todos", parte integrante do Acordo de Dacar (Senegal), assinado em 2000 (UNESCO, 2001). Entretanto, o 11 Relatório de Monitoramento Global de Educação para Todos (UNESCO, 2015), divulgado pela Organização das Nações Unidas para a Educação, a Ciência e a Cultura (Unesco), apontou que o compromisso assumido pelos 164 países, e, entre eles, o Brasil, de melhorar a qualidade da educação até 2015, não foi atingido globalmente. Em outro documento da UNESCO (2015, p. 7), a Declaração de Incheon para a Educação 2030, estabelece uma nova visão para a educação, onde "os sistemas educacionais precisam ser relevantes e responder prontamente a mercados de trabalho que mudam com rapidez, assim como a avanços tecnológicos".

A escola como espaço de aprendizagem pode proporcionar caminhos para esses desafios. Nesse sentido o Currículo Básico Comum - CBC (ESPÍRITO SANTO, 2009, p. 47) aponta que "a pesquisa motiva o aluno a protagonizar, expressar-se com autonomia, questionar, por meio de argumentações e defesa de hipótese, interpretar e analisar dados, construir e conhecer novos conceitos".

Em meio a um século de inovações é necessário visualizar e adotar novas práticas pedagógicas que promovam o entendimento das ciências e maior compreensão da Física. Em 2013 a Escola Estadual do Ensino Fundamental e Médio Professora Filomena Quitiba passou a utilizar o recurso Computação em Nuvem, na orientação dos trabalhos para a Feira de Ciências que já se tornou tradição ao longo dos anos. O recurso adotado é comum, pois requer apenas dos usuários um e-mail para 
desenvolver as atividades. Os integrantes compartilhavam o arquivo, em nuvem, facilitando assim a contribuição dos integrantes na elaboração do texto escrito sob supervisão dos professores orientadores. O uso desse recurso tecnológico facilitou bastante o trabalho de orientação, entretanto, uma parcela dos alunos ainda continuava com dificuldade de compreensão do método científico.

Em vista do exposto, o objetivo geral deste trabalho foi o de utilizar o Diagrama V como elemento instrucional e orientador da aprendizagem para a Feira de Ciências. Para isso, foram estabelecidos os seguintes objetivos específicos: (i) promover a compreensão do método científico por meio do Diagrama V; (ii) apresentar o Diagrama V como instrumento de compreensão e análise dos fenômenos que envolvem a Física na elaboração de trabalhos para Feira de Ciências.

\section{REFERENCIAL TEÓRICO}

\subsection{FEIRA DE CIÊNCIAS E DivUlgaÇÃo CIENTífICA}

As Feiras de Ciências são apontadas no Brasil como um recurso estratégico para o alcance da aprendizagem, promovendo o desenvolvimento de habilidades e estimulando a educação científica. A aplicação e utilização desse recurso no âmbito escolar permite a exploração o desenvolvimento de habilidade com enfoque na pesquisa, no método científico, em recursos tecnológicos, entre outros. Sobre as Feiras de Ciências o Ministério da Educação apresenta a seguinte definição:

[...] são eventos sociais, científicos e culturais realizados nas escolas ou na comunidade com a intenção de, durante a apresentação dos estudantes, oportunizar um diálogo com os visitantes, constituindo-se na oportunidade de discussão sobre os conhecimentos, metodologias de pesquisa e criatividade dos alunos em todos os aspectos referentes à exibição de trabalhos. (BRASIL, 2006, p. 20)

Ao participar de um evento social científico, em geral, os alunos encontram dificuldades em apresentar, por meio da comunicação oral, as teorias e conceitos envolvidos, utilizados e aplicados nos experimentos. O projeto de Feira de Ciências 
deve levar o aluno a entender sua responsabilidade em comunicar os resultados de seu trabalho, além de representar um dos mecanismos intencionais para alcançar a aprendizagem, que pode ser facilitada com o uso de ferramentas e, neste caso, como proposto por Gowin (1981), denominado aqui como Diagrama V. As atividades experimentais atraem os alunos e podem proporcionar a construção de conhecimento que se relaciona, de uma maneira mais próxima à sua realidade e ao conhecimento científico.

\subsection{TEORIA DE EDUCAÇÃO DE GOWIN}

David Bob Gowin $(1970,1981)$ elabora sua teoria para a educação com a proposição de elucidar o conhecimento, assim como a sua produção no meio educacional. Novak e Gowin (1984, p. 72) relatam a utilização do Diagrama V com alunos de ensino fundamental como heurística norteadora de atividades experimentais em sala de aula. A heurística de Gowin possibilita adaptações dependendo das condições de utilização e, como apontam os autores:

\footnotetext{
"aponta" para os acontecimentos e objetos que estão na base de toda a produção do conhecimento, [...] ajuda os estudantes a reconhecer a tensão e a interação que existe entre o conhecimento disciplinar que se vai construindo (e modificando) ao longo do tempo e o conhecimento que uma determinada investigação de momento realizada lhes permite construir. (NOVAK e GOWIN,1984, p. 73)
}

Novak e Gowin (1984) apontam o Diagramas V (Figura 1), como algo que se utiliza para ajudar a resolver um problema ou para entender um procedimento. Ou seja, constituem um meio de auxiliar educandos e educadores a visualizar a estrutura e o significado do conhecimento. 
Figura 1: O Diagrama V. Fonte: Ferracioli (2005).

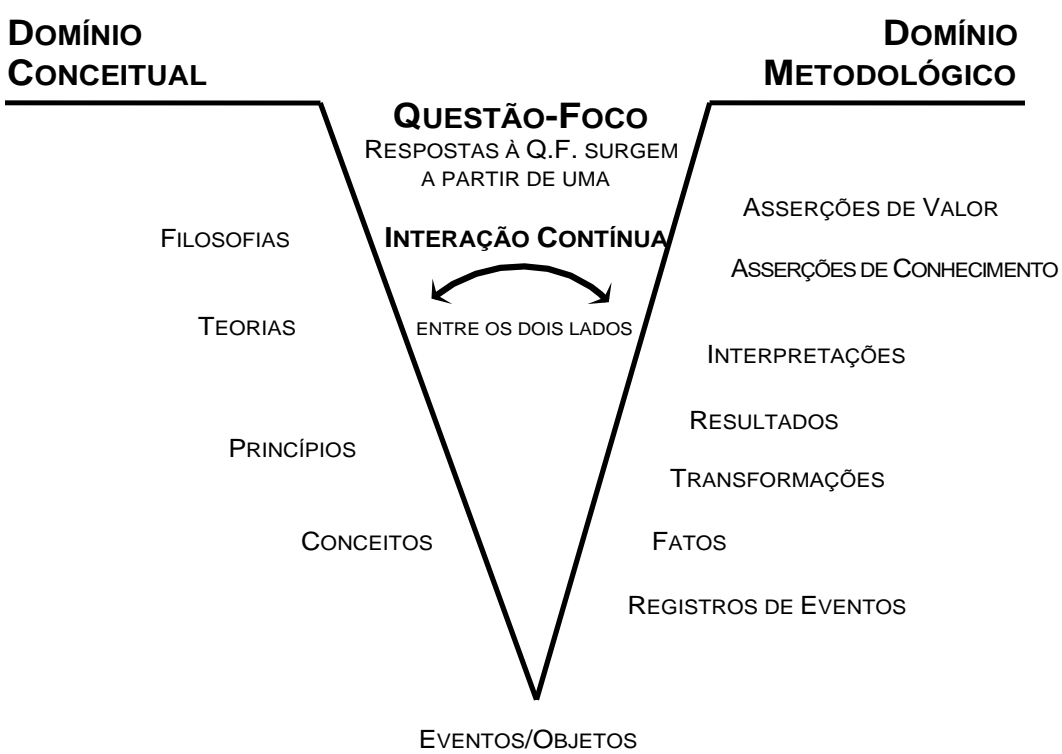

Para Novak e Gowin (1984), as questões clareiam o entendimento do Diagrama V e dão significado à temática da atividade experimental. Se bem utilizado, pode facilitar o trabalho docente e levar ao educando maior entendimento das atividades propostas, apresentando a potencialidade de elucidar o entendimento sobre o processo de obtenção de conhecimento, proporcionando a visão do todo quando há interação do lado esquerdo com o lado direito.

Para Cappelletto (2009, p. 52), o Diagrama V é uma "forma de educar a mente para pensar e examinar criticamente a estrutura do conhecimento de um trabalho".

Ferracioli $(2005 ;$ 2018) elucida que a pergunta direciona a pesquisa e as ações a serem tomadas. Os conceitos são formulados para culminar em uma base conceitual sólida.

Prado e Ferracioli (2017) relatam a utilização do Diagrama V como instrumento de orientação, coleta de dados e avaliação em atividades experimentais de eletromagnetismo para mostrar articulação entre teoria e prática em uma turma de Ensino Médio com 32 estudantes divididos em grupos de 3 e 4 integrantes para as três atividades experimentais. Os alunos apresentaram dificuldades para elaborar a 
Questão-Foco, ou seja, o problema da pesquisa. O uso do Diagrama V permitiu mapear erros conceituais por parte dos alunos, dificuldades em distinguir Conceitos com Leis e Princípios. E concluem que o Diagrama $\vee$ pode ser um instrumento norteador para o educando ao realizar atividade experimental.

Sobre o preenchimento do diagrama Vicentin e Santos (2015) afirmam:

Uma vez que pode ser utilizado pelo aluno, recomenda-se que, em um primeiro momento o professor auxilie o preenchimento do diagrama, juntamente com os alunos. Ao estarem familiarizados com o Diagrama $\mathrm{V}$, os alunos podem ter autonomia durante o seu preenchimento, cabendo ao professor apenas supervisionar a atividade para que as ideias possam ser melhoradas. (VICENTIN e SANTOS, pp. 75-100, 2015)

Nessa perspectiva o instrumento apresentado foi levado para dentro da Feira de Ciências e se mostrou poderoso no processo de investigação. O diagrama em formato de "V" é didático e possibilita ao educando visualizar os elementos fundamentais e suas interações com o trabalho científico.

\section{Percurso Metodológico}

A pesquisa quali-quantitativa foi desenvolvida na Escola Estadual de Ensino Fundamental e Médio Professora Filomena Quitiba, localizada no município de Piúma/ES que faz parte da microrregião sul do Espírito Santo. A opção pela região sul capixaba se fez pelo fato do autor do estudo ser Professor de Física da escola em questão.

Inicialmente foram localizadas as turmas para seleção dos sujeitos e posteriormente realizado o convite formal para a participação no estudo em atenção aos procedimentos do Mestrado Nacional Profissional em Ensino de Física - MNPEF vinculado ao Mestrado em Ensino de Física do PPGEnsFis da UFES - ES. Por fim, o estudo foi desenvolvido com alunos da 1a , 2aㅡ e 3a séries do Ensino Médio.

Os instrumentos de coleta de dados foram o Diagrama $V$ adaptado de Prado (2017) e o questionário elaborado por Alves (2016), com perguntas direcionadas aos 
participantes do estudo para obter informações para a tomada de decisões com fins de melhoramento contínuo do serviço educativo. As perguntas abordavam diversos aspectos dos elementos do Diagrama $V$, também, sobre confiança, interesse e entendimento ao fazer o experimento.

De acordo com Campoy Aranda (2016, p.163, tradução nossa), “o questionário consiste numa série de perguntas, normalmente de vários tipos, preparadas sistematicamente e cuidadosamente, por meio das quais se pretende obter informação sobre algum tema". Sampieri et al (2013, p. 310) afirma que é "o instrumento de pesquisa mais utilizado para coletar os dados, representando um conjunto de perguntas para uma ou mais variáveis a serem medidas".

Para a imersão do Diagrama $\vee$ foram realizadas duas Oficinas Pedagógicas realizadas com exposição oral com auxílio de Datashow em uma aula de 55 minutos. A primeira oficina teve o enfoque no Método Científico em preparação dos alunos para a segunda cujo enfoque foi o Diagrama $V$ propriamente dito, para promover a melhor compreensão do instrumento.

O Quadro 1 apresenta os tópicos da primeira oficina enquanto o Quadro 2 os tópicos da segunda oficina pedagógica.

Quadro 1: Programação da Primeira Oficina sobre o Método Científico.

\begin{tabular}{|c|c|}
\hline Temáticas & Etapas \\
\hline Teoria Científica & $\begin{array}{l}\text { - Poder explicativo } \\
\text { - Precisa dizer porque algo acontece, e não apenas o que } \\
\text { acontece... } \\
\text { - Resultado precisa ser validado... }\end{array}$ \\
\hline Método Científico & $\begin{array}{l}\text { - O que é Ciência? O que chamamos de conhecimento } \\
\text { científico? } \\
\text { - Visão idealizada: Problema } \rightarrow \text { Hipótese } \rightarrow \text { Experimento } \\
\rightarrow \text { Refutação/Não refutação } \rightarrow \text { Problema }\end{array}$ \\
\hline $\begin{array}{l}\text { Método Científico em } \\
\text { cinco partes }\end{array}$ & $\begin{array}{l}\text { - Observação: Entender seu objeto de estudo. } \\
\text { - Hipótese: Formular uma hipótese a partir da análise dos } \\
\text { dados. } \\
\text { - Previsões: Hipótese para predizer os resultados de } \\
\text { novas observações. }\end{array}$ \\
\hline
\end{tabular}




\begin{tabular}{|c|c|}
\hline & $\begin{array}{l}\text { - Experimento: Desenvolver experimentos para testar } \\
\text { suas predições. } \\
\text { - Teoria: Construir uma teoria que explica fenômenos. }\end{array}$ \\
\hline $\begin{array}{c}\text { Método Científico na } \\
\text { prática }\end{array}$ & $\begin{array}{l}\text { - Hipóteses precisam ser refutáveis } \\
\text { - Os experimentos precisam ser reprodutíveis } \\
\text { - Os resultados precisam ser comunicados } \\
\text { - Os métodos e resultados precisam ser criticados }\end{array}$ \\
\hline Tipo de Pesquisa & $\begin{array}{l}\text { - Nem toda pesquisa é feita da mesma forma, os métodos } \\
\text { são diversos. }\end{array}$ \\
\hline O método da Física & $\begin{array}{l}\text { - Formulação do problema } \\
\text { - Observação e experimentação } \\
\text { - Interpretação e formulação de hipóteses } \\
\text { - Teste da interpretação }\end{array}$ \\
\hline
\end{tabular}

Quadro 2: Programação da Segunda Oficina sobre Diagrama V.

\begin{tabular}{|c|c|}
\hline Temáticas & Diagrama V \\
\hline Partes do Diagrama V & $\begin{array}{l}\text { Dividido em } 4 \text { partes: Eventos, Questão(ões)-Foco, } \\
\text { Domínio Conceitual e Domínio Metodológico }\end{array}$ \\
\hline Vértice: Eventos & Acontecimentos ou fenômenos de estudo \\
\hline Centro: Questão-Foco & Pergunta da pesquisa relacionada ao evento. \\
\hline Questão(ões)-Foco & $\begin{array}{l}\text { É a pergunta que informa sobre o ponto central da } \\
\text { pesquisa. }\end{array}$ \\
\hline Evento & $\begin{array}{l}\text { Representa a origem da produção do conhecimento para } \\
\text { responder a Questão-Foco. }\end{array}$ \\
\hline $\begin{array}{l}\text { Domínio Conceitual - } \\
\text { Pensar }\end{array}$ & $\begin{array}{l}\text { Filosofias, Teorias, Princípios e os Conceitos que permite } \\
\text { elaborar a Questão-Foco }\end{array}$ \\
\hline Filosofia & São as visões de mundo \\
\hline Teoria & $\begin{array}{l}\text { Conjunto ordenado de princípios e conceitos para a } \\
\text { produção do conhecimento. }\end{array}$ \\
\hline Princípios & $\begin{array}{l}\text { Relação entre conceitos que guiam e orientam a } \\
\text { pesquisa. }\end{array}$ \\
\hline Conceitos & Regularidades percebidas em Eventos. \\
\hline $\begin{array}{l}\text { Domínio Metodológico - } \\
\text { Fazer }\end{array}$ & $\begin{array}{l}\text { Registro/Eventos, Fatos, Transformação, Resultados, } \\
\text { Interpretação, Asserções de Conhecimento e de Valor }\end{array}$ \\
\hline Registros/Dados/Fatos & $\begin{array}{l}\text { Observações efetuadas sobre os Eventos e catalogados e } \\
\text { posteriormente atribuímos como fatos. }\end{array}$ \\
\hline Transformações & $\begin{array}{l}\text { Análise dos registros: tabelas, gráficos, mapas, } \\
\text { estatística, correlações registros. }\end{array}$ \\
\hline $\begin{array}{l}\text { Asserções de } \\
\text { Conhecimento }\end{array}$ & $\begin{array}{l}\text { Conclusões a partir das análises dos dados que } \\
\text { respondem à Questão(ões)-Foco e leva ao resultado do } \\
\text { estudo }\end{array}$ \\
\hline Asserções de valor & $\begin{array}{l}\text { Significância e utilidade acerca do valor da pesquisa } \\
\text { baseados nas asserções de conhecimento. }\end{array}$ \\
\hline
\end{tabular}


O Quadro 3 retrata o quantitativo de aulas que foram destinadas para atender os 10 grupos e a relação dos trabalhos. Os integrantes dos grupos fizeram a montagem para expor diante da turma. Cada grupo entregou ao professor o Diagrama $\mathrm{V}$ preenchido, foi dado feedback durante as aulas sobre o lado direito do diagrama, que trata da ação. Durante a terceira aula, além de atender dois grupos, foi dado um tempo para que os integrantes dos grupos respondessem os questionários que foram devolvidos para ser posteriormente analisado.

Quadro 3: Culminância das atividades na sala de aula.

\begin{tabular}{|c|c|c|}
\hline \multirow{4}{*}{ 19 Aula } & Objetivo & $\begin{array}{l}\text { Discussão dos projetos com os grupos: } \\
\text { - Grupo 7: Futebol: um esporte reduzindo as } \\
\text { desigualdades } \\
\text { - Grupo 5: Stand Up ecológico } \\
\text { - Grupo 6: O Teorema Bernoulli e tubo de Venturi } \\
\text { - Grupo 4: O teorema de Arquimedes - Empuxo }\end{array}$ \\
\hline & Duração & Hora/Aula: 55 minutos \\
\hline & Formato & Aula experimental. \\
\hline & Descrição & $\begin{array}{l}\text { Os alunos montaram o experimento e } \\
\text { apresentaram o diagrama. Explicação do teorema } \\
\text { de Bernoulli. Exposição sobre Asserções de } \\
\text { Conhecimento e Asserções de valor. }\end{array}$ \\
\hline \multirow[t]{4}{*}{ 2a Aula } & Objetivo & $\begin{array}{l}\text { Orientação com os alunos para os projetos } \\
\text { - Grupo 1: Pressão, pressão atmosférica e } \\
\text { densidade } \\
\text { - Grupo 2: Prensa hidráulica: multiplicadora de } \\
\text { força de Pascal } \\
\text { - Grupo 3: Vasos comunicantes para determinar a } \\
\text { densidade de substâncias }\end{array}$ \\
\hline & Duração & Hora/Aula: 55 minutos \\
\hline & Formato & Aula experimental \\
\hline & Descrição & $\begin{array}{l}\text { Os grupos foram orientados sobre a montagem } \\
\text { dos vasos comunicantes e prensa hidráulica. } \\
\text { Preenchimento do Lado Metodológico do } \\
\text { Diagrama V. }\end{array}$ \\
\hline 3a Aula & Objetivo & $\begin{array}{l}\text { Realizar o experimento com o circuito montado } \\
\text { - Grupo 8: Primeira Lei de Ohm em operação } \\
\text { - Grupo 10: A Física no Enem: Fontes de geração de } \\
\text { energia elétrica }\end{array}$ \\
\hline
\end{tabular}




\begin{tabular}{|l|l|l|}
\hline Duração & $\begin{array}{l}\bullet \text { Grupo 9: Circuito série e paralelo: uma } \\
\text { abordagem experimental }\end{array}$ \\
\cline { 2 - 3 } Hora/Aula: 55 minutos \\
\cline { 2 - 3 } Fescrição & $\begin{array}{l}\text { Oula experimental. } \\
\text { a simulação da 1a lei de Ohm mediante Objeto } \\
\text { Digital de Aprendizagem (ODA), que chamou a } \\
\text { atenção dos demais alunos por ser virtual. }\end{array}$ \\
\hline
\end{tabular}

Os resultados são apresentados em formato variado como trechos dos relatos dos alunos, fotografias dos experimentos, Diagrama $\vee$ e gráficos. Os Diagramas $V$ produzidos foram avaliados conforme Alvarez e Gowin (2005) tabulados em 10 tabelas, cada item do diagrama recebe valor numérico que oscila entre 0 a 3 ou 4, a depender da investigação realizada e o enfoque do trabalho. O Diagrama $\vee$ possui vários elementos, por exemplo a Tabela 1, ilustra os critérios pra avaliar os conceitos.

Tabela 1: Critério de Avaliação para os Conceitos.

\begin{tabular}{c|l}
\hline Valor & \multicolumn{1}{c}{ Parâmetro de Avaliação } \\
\hline 0 & Nenhum Conceito é identificado \\
\hline 1 & $\begin{array}{l}\text { Conceitos são identificados, mas não estão relacionados com a Questão-foco } \\
\text { e/ou os Eventos. }\end{array}$ \\
\hline 2 & $\begin{array}{l}\text { Conceitos são identificados e estão relacionados com a Questão-foco e/ou os } \\
\text { Eventos. }\end{array}$ \\
\hline
\end{tabular}

\section{ApRESENTAÇÃO E DisCussão dOS RESULTADOS}

$\mathrm{A}$ análise do preenchimento dos itens do Diagrama $\vee$ dos grupos, ilustrados no Quadro 3, será apresentada através de gráficos. O Gráfico 1 apresenta os resultados para o item Questão-Foco. Dos 10 grupos, somente o grupo 1 não conseguiu elaborar este item, três grupos conseguiram (grupos 5, 7 e 10), porém não incluíram o Evento ou o lado Conceitual do V. Os outros seis grupos apresentaram a Questão-Foco, incluindo conceitos para serem usados e diretamente relacionados com o Evento. $\mathrm{O}$ grupo 1, na abordagem sobre pressão, fez uma relação na Questão-Foco, a saber, o 
fato de caminhar sobre a neve e a área dos sapatos. Em geral, uma parcela dos grupos estranhou a persistência da necessidade primordial da Questão-Foco nos trabalhos científicos.

Gráfico 1: Questão-Foco dos diagramas. Fonte: Dados da pesquisa.

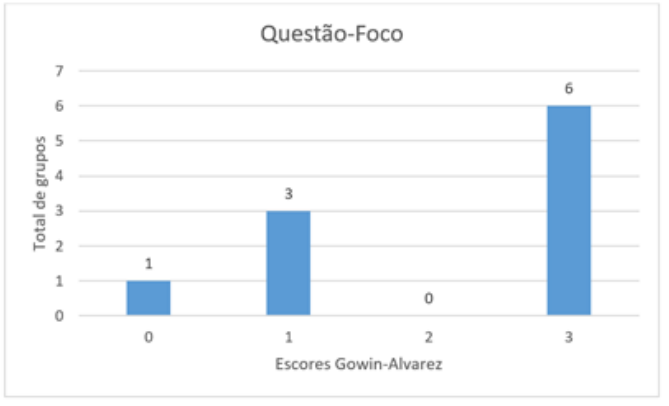

Gráfico 2: Conceitos nos diagramas. Fonte: Dados da pesquisa.

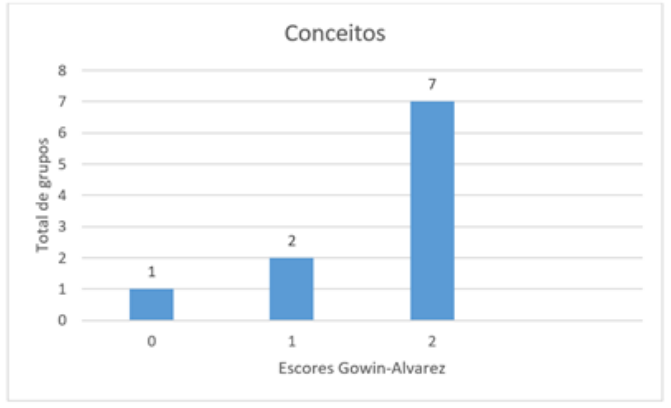

O item Conceitos, ilustrado no Gráfico 2 retrata, para dois grupos (2 e 10), que os Conceitos são identificados, mas não estão relacionados com a Questão-foco e/ou os Eventos. O grupo 2 'Prensa hidráulica: multiplicadora de força de Pascal' apresentou conceitos insuficientes, faltou acrescentar a força para relacionar com a Questão-foco e/ou os Eventos. O grupo 10 'A Física no Enem: Fontes de geração de energia elétrica' conseguiu identificar os Conceitos, mas não estão relacionados com a Questão-foco e/ou os Eventos. O quinto grupo 'Stand Up ecológico', nenhum Conceito. Os demais grupos trouxeram os conceitos corretos nos diagramas.

Os 10 grupos tiveram facilidade no quesito Evento, ao colocarem dados necessários para construir o experimento de acordo com a Questão-foco. A tradição 
da escola em realizar o evento Feira de Ciências há trinta e seis anos possibilita aos alunos maior facilidade com este elemento constitutivo do Diagrama V.

O item Registros/Dados (Gráfico 3) não foi identificado no trabalho do grupo 6, 'O Teorema Bernoulli e tubo de Venturi'. Outros quatro grupos $(5,7,8$ e 10) apresentaram Registros/Dados, mas são inconsistentes com a Questão-foco ou com o Evento. Os demais grupos (1, 2, 3, 4 e 9) foram coerentes com este item do Diagrama $\checkmark$ ao relacioná-lo ao Evento e a Questão-Foco. Os elementos constitutivos do Diagrama V, segundo Novak e Gowin (1984, p. 125), "funcionam de forma normativa para estabelecer os critérios de valor. Uma boa porção de conhecimento deverá incluir todos os elementos do "Vê", ilustrar como é que esses elementos se ligam entre si, e ser coerente, compreensiva e significativa".

Gráfico 3: Registro/Dados nos diagramas. Fonte: Dados da pesquisa.

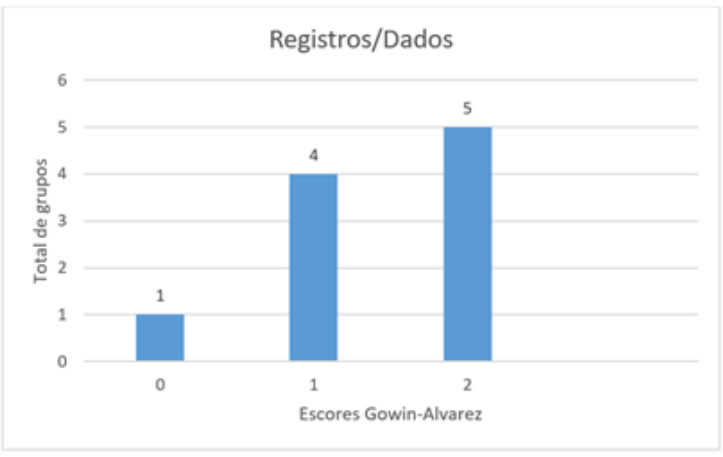

Gráfico 4: Transformações nos diagramas. Fonte: Dados da pesquisa.

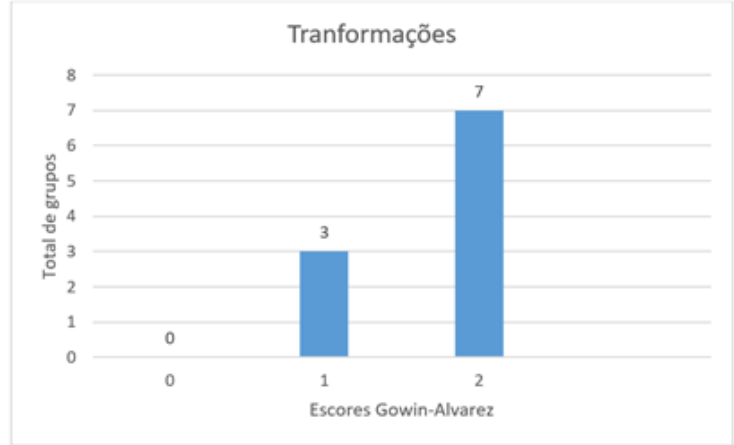

No Gráfico 4, 'Transformações', observa-se um bom desempenho, 70\% dos grupos conseguiram transformar os dados em consonância com a Questão-Foco. Três 
grupos (1, 5, e 10), que representam 30\%, não tiveram o mesmo êxito pois não conseguiram interligar. Registros muito incompletos e incoerente com a QuestãoFoco. O grupo 'Vasos comunicantes para determinar a densidade de substâncias' fez a demonstração do teorema de Stevin e obtiveram a expressão que relaciona a densidade (d) e a altura (h) do fluido dentro do tubo em U. O Grupo 6 'O Teorema Bernoulli e tubo de Venturi', ilustrado na Figura 2, também fez uma demonstração por meio da equação de Bernoulli até obter a expressão matemática da velocidade com que o fluido deva sair do tubo de Venturi. Para obtenção da expressão o orientador ajudou os alunos do grupo, pois o livro didático só traz a equação de Bernoulli, que permite estudar a energia de escoamento.

Figura 2: Experimentos - Teorema Bernoulli/tubo de Venturi e Futebol: um esporte reduzindo as desigualdades (efeito Magnus). Fonte: Dados da pesquisa.
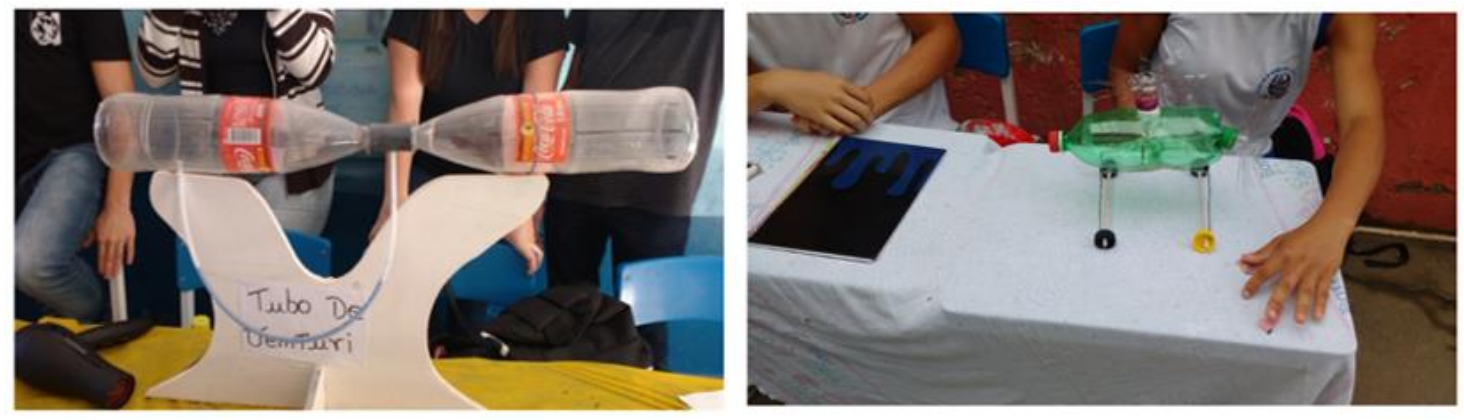

O Grupo 8, 'Primeira Lei de Ohm em operação', apresentou o gráfico da corrente versus diferença de potencial. Os demais grupos foram assertivos no item Transformações.

O quesito Conclusões e Justificativas, ilustrado no Gráfico 5, traz resultado satisfatório, apesar de que o grupo 5 'Stand Up ecológico', não ter apresentado a conclusão do trabalho. O grupo 1 'Pressão, pressão atmosférica e densidade' apresentou Conclusões, mas inconsistentes com a Questão-foco. Os grupos 2 e 3 grupos apresentam Conclusões, derivadas dos Registros e Transformações. Quatro grupos (4, 6, 8 e 9) apresentaram Conclusões consistentes com os dados coletados nos 
Registros e representados nas Transformações. Dois grupos, 'O Teorema de Arquimedes - empuxo' e 'Futebol: um esporte reduzindo as desigualdades', trazem as Conclusões, que contêm os componentes com os dados coletados nos Registros e representados nas Transformações e sugerem novas Questão (ões)-foco. O Grupo 'Pressão, pressão atmosférica e densidade', trouxe um medidor de pressão arterial e estabeleceu uma relação do conceito de pressão com o cotidiano. Mas, o trabalho vinha sendo desenvolvido para determinar a densidade e no final os integrantes optaram pela mudança de direção, fugindo da intenção inicial do trabalho.

Gráfico 5: Conclusões e Justificativas nos diagramas. Fonte: Dados da pesquisa.

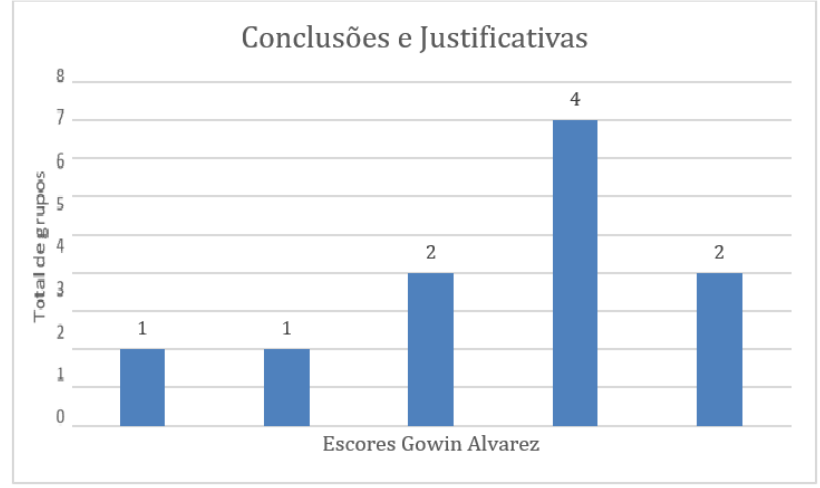

O Grupo 'Primeira Lei de Ohm em operação' (Figura 3), concluiu que: “A primeira Lei de Ohm afirma que a corrente elétrica que atravessa um dispositivo qualquer é sempre diretamente proporcional à diferença de potencial aplicada a esse dispositivo". Este grupo foi o único a trabalhar com simulação para mostrar um conteúdo da Física. Utilizou um recurso da Plataforma Sedu Digital ${ }^{1}$, que é um Objeto Digital de Aprendizagem (ODA).

1 Cf. https://curriculointerativo-sedu-es-gov-br.escoladigital.org.br/odas/eletricidade-lei-de-ohm. Acesso em 23-042018. 
Figura 3: Experimentos: Primeira Lei de Ohm em operação (Simulador). Fonte: Sedu Digital.

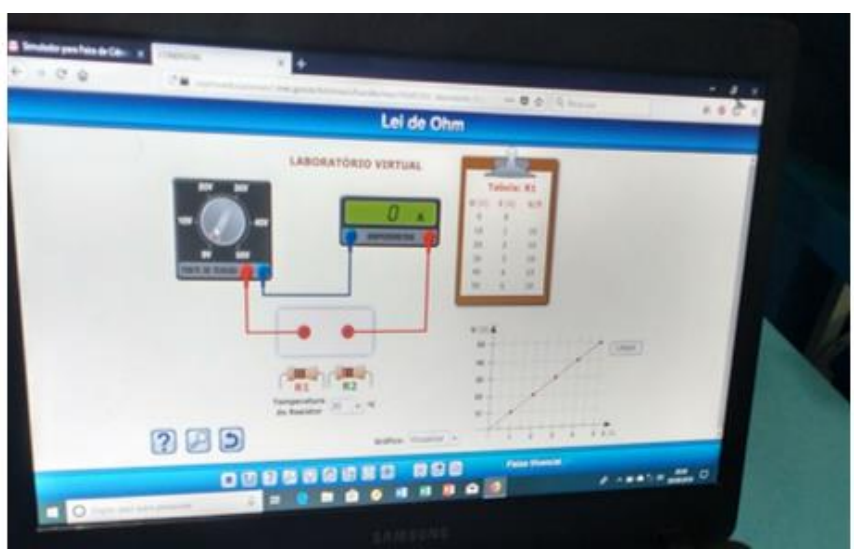

O Grupo 'Circuito série e paralelo: uma abordagem experimental' também conseguiu apresentar as Conclusões e Justificativas, perpassando por Registros e Transformações, com propósitos de mostrar as associações em série e em paralelo no cotidiano das pessoas da comunidade local.

A Figura 4 ilustra o Diagrama V do grupo 8 'Primeira Lei de Ohm em operação' da terceira série que foi preenchido de forma adequada e posteriormente digitalizado pelos integrantes da equipe. 
Figura 4: Diagrama V do grupo Primeira lei de Ohm em operação. Fonte: Dados da pesquisa.

\section{Oficina Pedagógica do Diagrama de Gowin / Feiras de Ciências}

\section{Primeira Lei de Ohm em Operação}

Terceiro ano: Bianca Júnia, Thaislayne, Gustavo, Felipe Prof. Lucas Antonio Xavier

EEEFM Professora Filomena Quitiba - lucas. perobas e gmailcom

XXXV Feira de Cièncias da Escola Professora Filomena Quitiba

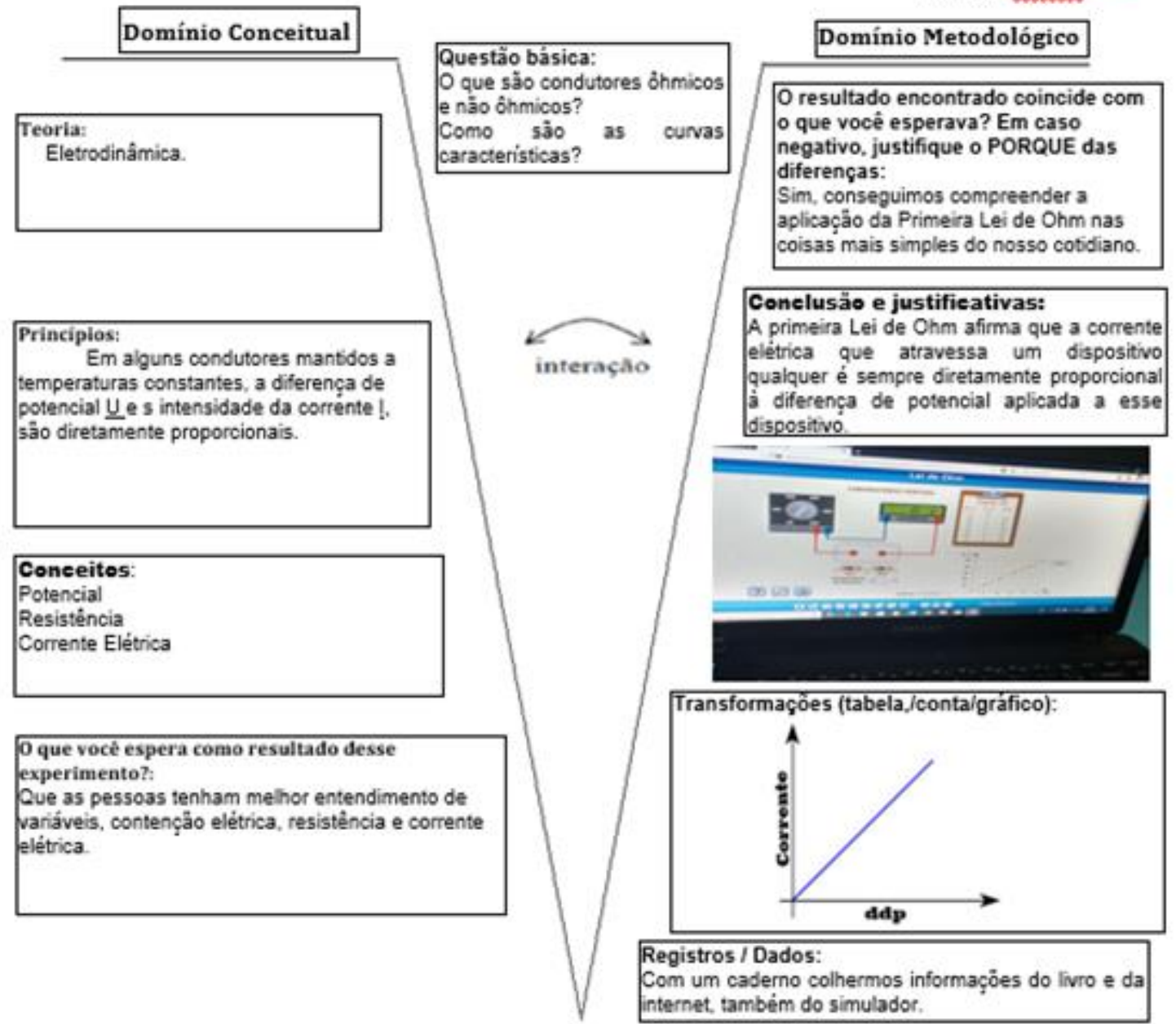

Evento (Montagem do equipamento/experimento):

Expentencia: simulador vitual

O que foi feito:

Com o computador ligado acessamos o site hitips:licurriculointerativo-sedunes-oov.

br.escoladigital org briodas/eletricidade-lei-de-ohm para

iniciar a simulaçăo de circuito de dois resistores. Adicionamos um resistor de cada vez e variamos a voltagem.

\section{que foi observado:}

De acordo com a variaçăo da voltagem a corrente mudava,

percebido pela tabela e quando observamos o gráfico gerado, os integrantes do grupo perceberam a reta. Ao interpretar vimos que a resistência ficava constante.

Os dez grupos que utilizaram o Diagrama $\vee$ nos projetos para a Feira de Ciência responderam a um questionário contendo 15 questões. As respostas a algumas 
questões serão discutidas por meio dos resultados apresentados em gráficos. Sobre o uso da Heurística de Gowin o Gráfico 5 apresenta os resultados que foram satisfatórios.

Gráfico 5: Inserção do Diagrama V na Feira de Ciência.

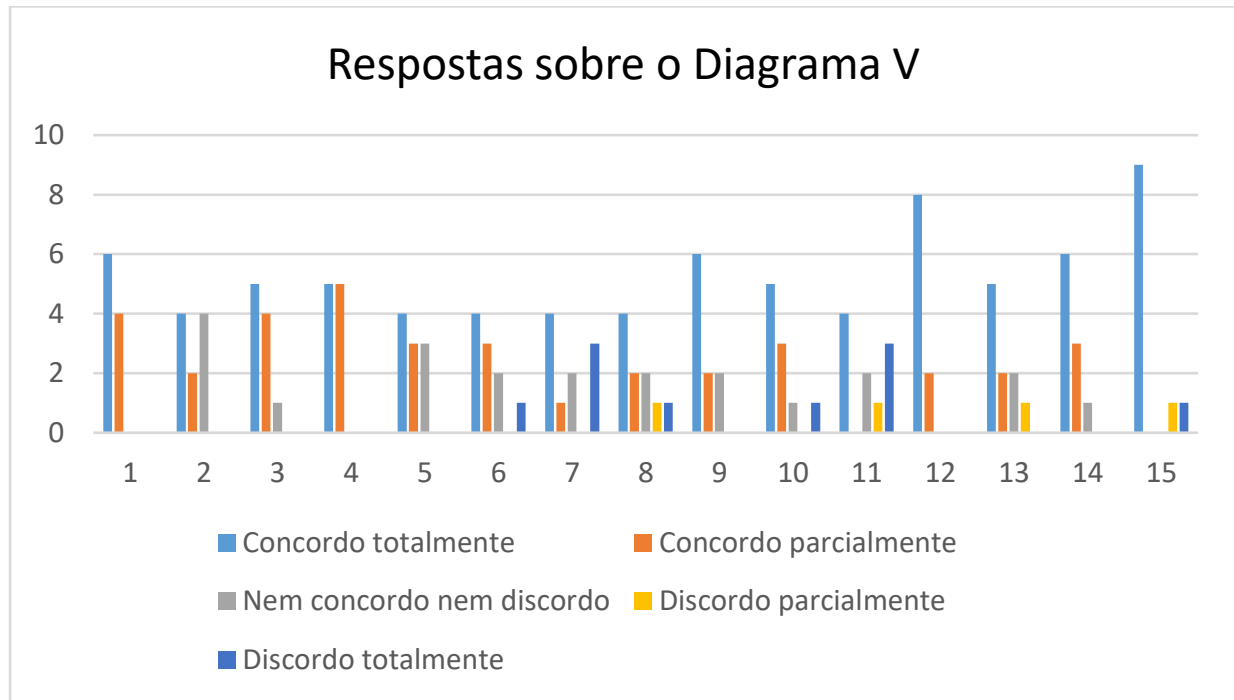

Quanto à primeira questão: 'Eu gostei de usar o Diagrama V para a Feira de Ciências', $60 \%$ dos grupos concordam totalmente e $40 \%$ disseram que concordam parcialmente. Moreira (2012, pp. 3-12) pontua que o Diagrama V é um facilitador de uma aprendizagem significativa em ciências.

Sobre a terceira questão: 'O Diagrama $\vee$ me ajudou a aprender os CONCEITOS usados nos experimentos' $50 \%$ concordam totalmente, $40 \%$ concordam parcialmente e $10 \%$ nem concordam e nem discordam.

Em relação à sexta questão ‘No início do semestre, senti-me desconfortável para elaborar o Diagrama $V^{\prime}, 40 \%$ concordam totalmente, 30\% discordam parcialmente, $20 \%$ nem concordam e nem discordam e $10 \%$ discordam totalmente.

Quanto à nona questão: 'O Diagrama $\vee$ me ajudou a entender melhor o que eu estava fazendo no experimento', $60 \%$ concorda totalmente, $20 \%$ concordam parcialmente e outros $20 \%$ nem concordam e nem discordam. 
Em se tratando da questão 15: 'A disponibilidade do professor para tirar minhas dúvidas foi essencial para a compreensão do Diagrama V', $90 \%$ concordam totalmente e $10 \%$ discordam parcialmente.

Em relação aos efeitos da realização da Feira de Ciências (Figura 5) na escola, foi aplicado um questionário (enquete) com a intenção de obter as percepções de alunos e visitantes com relação ao evento.

Figura 5: Culminância: Feira de Ciências. Fonte: Dados da pesquisa.

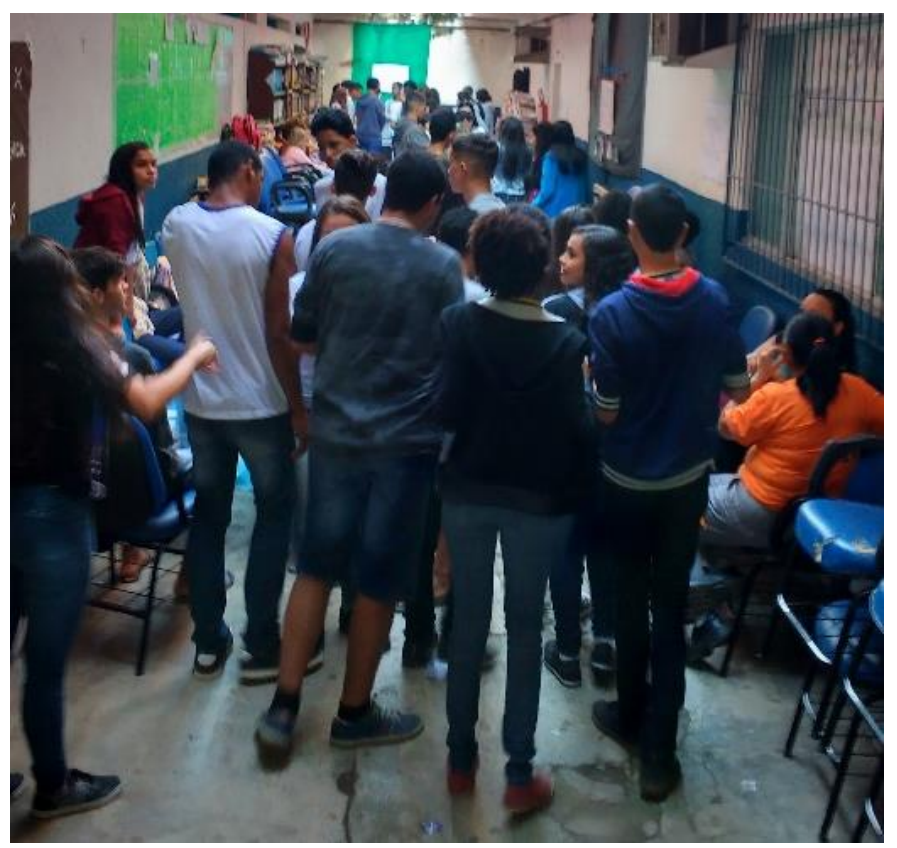

Sobre as vantagens do evento científico, os professores, em face das próprias experiências em sala de aula, pontuaram: estímulo a pesquisa, interação, conhecimento, pesquisa, formação científica, e desenvolvimento dos alunos, entre outras; os alunos, participantes da feira, destacaram a motivação, aprendizagem, nova metodologia, interação com a comunidade, possibilidade de expor os projetos, entre outros. Com relação aos pontos negativos, tanto professores quanto alunos, foram enfáticos: espaço físico, tumulto, muito barulho para ouvir as explicações, falta de suporte aos alunos por parte da escola, atrito entre alunos, etc. O Quadro 4 evidencia 
a percepção dos alunos ao apontar os pontos positivos e negativos do evento científico

da escola. A estudante B não aponta os pontos negativos em sua narrativa.

Quadro 4: Depoimento dos estudantes coletada na Feira de Ciência. Fonte: Dados da pesquisa.

Estudante A - [...] pontos positivos: desenvolvimento em grupo, comunicação entre indivíduos, estimulo à inovação científica. [..,] Pontos negativos: falta de um espaço melhor, não colocar os projeto em prática, desorganização do evento.

Estudante B - [...] pontos positivos: ter mais conhecimento, aprender coisas diferentes, reconhecimento dos professores, ser elogiado pelo público [.,,] Pontos negativos:

Estudante C - [...] pontos positivos: contato com a ciência, desenvolvimento de talentos, agregação de conhecimento, indo para a realidade, os pontos positivos, que ajudam as pessoas que não têm facilidade em exatas a conseguir bons pontos para não reprovar e também é dever internamente expor os experimentos. [.,,] Pontos negativos: gasto com dinheiro, e indo para a realidade; pontos negativos é a maioria não entender por ciência, trabalhos meia boca só pra conseguir nota.

\section{CONSIDERAÇÕES FINAIS}

A metodologia da utilização do Diagrama $V$ de Gowin como elemento instrucional e orientador da aprendizagem para a Feira de Ciências ressaltou o grau de liberdade para o educando compreender sua atividade experimental e apresentar os conceitos aprendidos durante todo o processo mediado pela heurística de Gowin. Em alguns trabalhos dos estudantes, a dialogia do lado esquerdo (pensar) com o lado direito (fazer) no diagrama possibilitou o início da compreensão dos fundamentos científicos numa perspectiva teórico experimental.

Além de propiciar, em parte, a compreensão do método científico por meio do Diagrama $\mathrm{V}$, as oficinas realizadas foram fundamentais por representarem domínios não explorados nas aulas de Física da escola. Para fazer ciência é necessário a sistematização das ideias e o método é o melhor caminho na busca do conhecimento a ser compartilhado.

Na segunda oficina, ao elencar os elementos constitutivos do Diagrama $V$, que trata, segundo Ferracioli (2005; 2018), da mimetização do método científico na construção do conhecimento, foi possível apresentar ao aluno a cultura científica, da 
organização do Evento, da formulação da Questão-Foco, identificação dos elementos do Domínio Teórico, da obtenção de Registros/Dados, para serem transformados e obter as Asserções de Conhecimento e de Valor.

O Diagrama $V$, como instrumento de percepção e análise da Física, também evidenciou a dificuldade dos alunos em relação a alguns elementos que remetem às teorias e princípios estudados na disciplina. Como exemplo, nos itens Registros/Dados e Transformações, houve imprecisão ao trabalharem com os conteúdos da Física nos experimentos, acarretando incoerência na conclusão da tarefa.

No século XXI, com a sociedade de informação, levar a cultura do método científico para a sala de aula, torna uma necessidade, pois em acordo com as diretrizes curriculares:

Uma atitude de inquietação diante da realidade potencializada pela pesquisa, quando despertada no Ensino Médio, contribui para que o sujeito possa, individual e coletivamente, formular questões de investigação e buscar respostas em um processo autônomo de (re)construção de conhecimentos. (BRASIL, 2013, p. 164)

A inquietação diante da realidade precisa ser reconhecida no aluno e também no professor que, no contexto da educação atual, atua como principal mediador, propondo metodologias e estratégias para potencializar o processo de ensino e aprendizagem.

Nessa perspectiva espera-se com este trabalho ter contribuído, apesar de muitos outros desafios, para a reflexão/compreensão do potencial da presença do Diagrama $\checkmark$ na Feira de Ciências. A inserção da heurística de Gowin no evento científico proporcionado anualmente pela escola professora Filomena Quitiba foi positiva ao proporcionar aos alunos melhor compreensão da importância do método científico.

Em acordo com a Declaração de Incheon (UNESCO, 2015, p. 9), "uma parte integrante do direito à educação é garantir que a educação tenha qualidade suficiente 
para gerar resultados de aprendizagem relevantes, equitativos e eficientes em todos os níveis e contextos".

Para as próximas pesquisas é recomendável aprofundar as discussões sobre a forma como o Diagrama $V$ pode ser infundindo em todas as atividades das disciplinas da educação básica, de forma que o método possa agregar conhecimento no campo educacional por meio de suas potencialidades.

\section{AGRADECIMENTOS}

À CAPES (Coordenação de Aperfeiçoamento de Pessoal de Nível Superior) e ao CNPQ (Conselho Nacional de Desenvolvimento Científico e Tecnológico) pelo apoio financeiro por meio da bolsa concedida. 


\section{REFERÊNCIAS}

ALVES, Vitória Jamile Lira. O fazer não pressupõe o aprender: o uso do Vê de Gowin no Laboratório de Química Fundamental. 2016. Disponível em: http://bdm.unb.br/handle/10483/17477. Acesso em 22-03-2018

BRASIL. Orientações curriculares para o ensino médio: Ciências da Natureza, matemática e suas tecnologias. Volume 2. Secretaria de Educação Básica. Brasília: Ministério da Educação. Secretaria de Educação Básica, 2006.

BRASIL. Diretrizes Curriculares Nacionais Gerais da Educação Básica/ Ministério da Educação. Secretária de Educação Básica. Diretoria de Currículos e Educação Integral. - Brasília: MEC, SEB, DICEI, 2013.

Campoy Aranda, Tomás Jesús. Metodologia de la Investigación científica. Ciudad del Este: Escuela de Posgrado, Universidad Nacional del Este, 2016.

CAPPELLETTO, Eliane. O Vê de Gowin conectando teoria e experimentação em física geral: questões didáticas, metodológicas e epistemológicas relevantes ao processo. Porto Alegre, 297 p., 2009. Dissertação (Mestrado) - Universidade Federal do Rio Grande do Sul.

ESPÍRITO SANTO. Currículo Básico Escola Estadual - CBC; v. 02. Secretaria da Educação, SEDU. Ensino médio: área de Ciências da Natureza. Vitória, Brasil, 2009.

FERRACIOLI, Laércio. O Ensino de Física no Estado do Espírito Santo. In: Sidnei Leite. (Org.). Práticas Experimentais Investigativas em Ensino de Ciências. 1ed. Vitória, ES: 2012, v. 1, p. 36-41.

FERRACIOLI, Laércio. O Diagrama V no Ensino Experimental. 2018, Publicação Interna do ModeLab. Departamento de Física, Universidade Federal do Espírito Santo.

FERRACIOLI, Laércio. O V Epistemológico como Instrumento Metodológico para o Processo de Investigação. Revista Didática Sistêmica, v.1, n.1, p. 106-25, 2005. Disponível em: <http://www.mettodo.com.br/pdf/V_de_Gowin.pdf>. Acesso em: 19 de março de 2017.

GOWIN, David B. Educating. New York: Cornell University Press, 1981.

GOWIN, David B.; ALVAREZ, M. C. The Art Educating with V Diagrams. Cambridge University Press, New York, 2005.

FERRACIOLI, Laércio. O ensino de Física no Estado do Espírito Santo. In: Práticas experimentais investigativas em ensino de ciências: caderno de experimentos de física, química e biologia - reflexões sobre o ensino de ciências. / Sidnei Quezada Meireles Leite, organizador. - Vitória, ES: Instituto Federal de Educação, Ciência e Tecnologia do Espírito Santo, 2012. Disponível em: 
<http://educimat.ifes.edu.br/images/stories/Publica\%C3\%A7\%C3\%B5es/Livros/Ifes_L ivro-Praticas-Experimentais-_2012.pdf>. Acesso em: 03 de fevereiro de 2018.

MINTZES, J. J., WANDERSEE, J. H., NOVAK, J. D. Assessing Science Understanding: A Human Constructionist View. San Diego, EUA: Elsevier Academic Pres, P. 55, 1999.

MOREIRA, Marco Antonio. Diagramas V e Aprendizagem Significativa. Revista Chilena de Educación Científica, v. 6, N. 2, pp. 3-12, 2007. Revisado em 2012.

MURRELEKTRONIK. Entendendo a Indústria 4.0: Como oferecer as melhores automações de máquinas. Murrelektronik. E-book. Agência/mestre. https://www.murrelektronik.com.br/ acesso em 23-02-2019.

NOVAK, Joseph D.; GOWIN, David B. Aprender a Aprender. 1. ed. Lisboa: Cambridge University Press, 1984.

PRADO, Ramon Teodoro do; FERRACIOLI, Laércio. Utilização do Diagrama $V$ em Atividades Experimentais de magnetism em Sala de Aula de Ensino Médio. Revista do professor de Física, v. 1, p. 1-14, 2017.

PEREZ, C. P. O que nos mostram as avaliações em Ciências: o triste cenário brasileiro. Comciência, Campinas/SP, 10 fev. 2015. Disponível em: http://www.comciencia.br/comciencia/handler. .php?section=8\&edicao=110\&id=1317 . Acesso em: 02 de novembro de 2018.

SAMPIERI, Roberto Hernández, COLLADO, Carlos Fernández, \& LUCIO, Pilar Baptista. Metodologia de Pesquisa, 5th edição. AMGH, 03/2013. [Minha Biblioteca].

UNESCO. Education 2030: Incheon Declaration and Framework for Action: towards inclusive and equitable quality education and lifelong learning for all. Brasília: UNESCO, 2016. Disponível em:<http://www.unesco.org/new/pt/brasilia/about-thisoffice/single-

view/news/education_2030_incheon_declaration_and_and_framework_for_ac/>. Acesso em 11-03-2019.

UNESCO. Educação para todos 2000-2015; progressos e desafios. Relatório Conciso. Relatório de Monitoramento global de EPT 2015. Unesco brasil. Brasília, DF: Unesco no Brasil, 2015.

VICENTIN, J.; SANTOS, S. A. O ensino do conceito de pressão a partir de uma abordagem integradora, com o apoio de mapas conceituais, diagramas ADI (atividades demonstrativo-interativas) e experimentos alternativos na 8 a série do Ensino Fundamental.

em: $<$ http://www.diaadiaeducacao.pr.gov.br/portals/pde/arquivos/1616-8.pdf>. Acesso em 28 de dezembro de 2018. 